\title{
Approaches to Evaluate and Develop Health Risk-Based Standards Using Available Data
}

Inés Navarro, Peter Teunis, Christine Moe and Blanca Jiménez

\begin{abstract}
Information on the dose-response relationship of waterborne and foodborne enteric pathogens is an important component in any consideration of the health risks that may be associated with wastewater, sludge or excreta reuse for food-crop production. The three main sources of information on dose-response relationships are: human challenge studies, animal studies and outbreak investigations. Doseresponse information on four representative enteric pathogens (Norwalk virus, $E$. coli $\mathrm{O} 157: \mathrm{H} 7$, Giardia lamblia and Ascaris lumbricoides) is presented as examples. In addition to dose-response information, the application of quantitative microbial risk assessment to examine the potential health risks associated with the consumption of food crops irrigated with wastewater or fertilized with biosolids requires information on several factors. These are transmission pathways, occurrence (frequency and concentration) of pathogens in wastewater and biosolids, persistence of pathogen viability or infectivity in the environment and on the food crops, and crop consumption (amount and frequency). Assessments of the risks of Giardia and Ascaris infection associated with food crops in several scenarios are presented and illustrate how WHO Guidelines and pathogen reduction measures (such as produce-washing) may have a significant or negligible impact on reducing the risks of infection associated with food crops irrigated or fertilized with wastewater and biosolids.
\end{abstract}




\section{INTRODUCTION}

The WHO Guidelines for the Safe Use of Wastewater, Excreta and Greywater (WHO, 2006) are based on the development and use of health-based targets, with the goal of attaining a certain level of health protection in an exposed population. This level of health protection can then be achieved by using a combination of risk-management approaches (e.g. crop restriction, safer application techniques, human-exposure control) (WHO, 2006). In some situations it is not possible to fully implement the desired level of protection at a given time. For this reason, the WHO Guidelines suggest designing regulations that allow progressive implementation. This can be attained over time in an ordered manner, depending on the circumstances and resources of each individual country or region. In order to achieve this, each country should try to develop a risk-management plan based on local context. For example, in the WHO Guidelines, a general pathogen reduction of 6-7 $\log$ units is used as a safe performance target for unrestricted irrigation (see Chapter 2).

In order to adjust the target to locally relevant pathogens and ways of wastewater application, quantitative microbial risk assessment (QMRA) can be used as one possible tool. The quality of the QMRA analysis depends largely on the availability of dose-response information. This information indicates the relationship between exposure to specific doses of a pathogen and the probability of developing infection and/or symptoms in the exposed host. Dose-response relationships depend on virulence characteristics of the pathogen as well as host susceptibility factors. For prediction of risk it is necessary to estimate the probability of infection, conditional on exposure, and the probability of (acute) illness, conditional to infection. Without exposure, infection cannot occur and, similarly, without infection, a person cannot become ill. This apparently trivial statement has important consequences for quantitative risk assessment: if exposure assessment indicates that the probability of exposure is smaller than a certain level, the probabilities of infection, as well as illness, generally cannot exceed that level of risk. Some micro-organisms are highly infectious, such as the Norwalk virus example described later in this chapter. Exposure to even low doses of highly infectious agents may be associated with significant risk of infection and illness.

Information on the dose-response relationship of waterborne and foodborne pathogens is an important component in any consideration of health risks that may be associated with wastewater, sludge and excreta irrigation or reuse for crop production. The available information on dose-response for enteric pathogens comes from three main sources: human challenge studies, animal challenge studies and outbreak investigations. This chapter will examine these sources of information and considerations for their use for risk assessment, taking into account different types of micro-organisms of concern. Dose-response information on four representative enteric pathogens will be presented as examples. The application of 
the WHO (2006) procedure to develop recommendations to reduce the risks of pathogen exposure is the same regardless of the type of pathogen, therefore in this chapter only its application to helminth (Ascaris) eggs is described.

\section{HuMAN CHALLENGE STUDIES}

Perhaps the most reliable dose-response information comes from human challenge studies where both the exposure and response can be well characterized. In these studies, exposure (i.e. dose) is controlled by administering various dilutions of a pathogen suspension. This inoculum must undergo rigorous safety-testing to ensure that it only contains the target pathogen and no other harmful substance. Also, the suspension needs to be titrated - by culture (for bacteria and some viruses) and polymerase chain reaction (for some viruses), or by microscopic counts or particle counts of cysts, oocysts or ova (for parasites and helminths). However, the exact number of the target pathogen that is ingested (or inhaled, for airborne exposure) in each dose is not known but must be estimated from information on the titre of the suspension and the dilution. For that reason, the estimation of exposure is part of the dose-response assessment.

The exponential and beta-Poisson models (see below) are two dose-response relationships that can be developed from biologically plausible assumptions about the infection process. Best-fit dose-response parameters for these models for a number of human pathogens were summarized by Haas and Eisenberg (2001).

The use of human volunteers limits the range of pathogens in human challenge studies to relatively mild pathogens that cause mild symptoms that are either self-limited or resolved by treatment and are not associated with any long-term adverse health effects. These studies are therefore subjected to careful review by ethical boards to ensure that the health, privacy and human rights of the volunteers are fully protected. For ethical reasons, these studies usually only involve healthy adult subjects who are able to understand the study protocol and give informed consent to participate in the study. All candidate volunteers are screened for good health and immune competence before being enrolled into the study in order to ensure that the experiments have no serious consequences for those involved. The volunteers who receive the pathogen inoculum are usually admitted into a clinical research unit so that their symptoms can be carefully monitored and recorded and so that they can receive appropriate medical care if needed. Specimens of stool, sera, whole blood, saliva, vomitus and, sometimes, intestinal biopsies are collected on a routine basis before and after, to test for infection indicators. Infection may be characterized by excretion of the challenge pathogen as detected in stool and vomitus specimens or by immune response, for example, a rise in pathogen-specific serum or salivary antibodies, or evidence of a cellular immune response. 


\section{Role of immunity}

One factor that must be considered in both quantitative microbial risk assessment and the information from dose-response studies of infectious agents is the role of previous exposure and possibly protective immunity in human challenge studies. For common enteric pathogens, such as norovirus and Cryptosporidium, it is likely that many candidate volunteers may have had previous infections with these pathogens and that this previous exposure/infection may have an impact on the host response to challenge. In studies of norovirus infectivity, the presence of norovirus-specific antibodies in sera appeared to be a marker of susceptibility to norovirus infection and did not seem to provide protection (Lindesmith et al., 2003). In studies of Cryptosporidium infectivity, those volunteers who were serologically naive for Cryptosporidium were significantly more likely to develop infection after the challenge than volunteers who had higher measurable titres of serum antibodies against Cryptosporidium (Teunis et al., 2002b).

The challenge of protective immunity limits the transfer of dose-response models from industrialized to developing countries if the specific pathogen exposure is significantly different. One example of this is hepatitis A virus where results based on external dose-response models are likely to overestimate the risk for large parts of the local population who may have had hepatitis A infection during childhood and are no longer susceptible to infection. The QMRA can address this challenge in its calculations.

\section{Heterogeneity in strain virulence and host susceptibility}

The variation in infectivity among different isolates from (genetically) the same pathogen species has been shown to be considerable, at least as large as differences between different species (Chen et al., 2006; Teunis et al., 2002a). Similarly, variation in susceptibility to infection and illness among human hosts can be large (Teunis et al., 2002b, 2005). In a Norwalk virus challenge study, volunteers with blood group $\mathrm{O}$ were significantly more susceptible to infection than other blood types, and blood group A appeared to be less susceptible to infection. In addition, a group of volunteers that was completely resistant to Norwalk virus infection and illness was observed, and this resistance was attributed to genetic factors that may code for the virus binding site (Lindesmith et al., 2003). Finally, it is useful to note that most pathogens are initially identified in outbreaks of disease, where the most virulent strains tend to be detected and the most susceptible hosts tend to become ill. However, in human challenge studies, the hosts are screened and selected for their health and the challenge organisms tend to be less virulent in terms of illness. Thus, data from outbreaks and human challenge studies - that unfortunately are mostly performed in developed countries - tend to represent opposite ends of the dose-response continuum. 


\section{ALTERNATE SOURCES OF DOSE-RESPONSE INFORMATION}

The problems associated with finding appropriate dose-response data, even for dangerous pathogens, have led risk assessors to consider surrogate data: surrogate pathogens, hosts or both.

\section{Animal challenge studies}

A human pathogen may often be adapted to its host, rendering its response in a surrogate host species distinctly different from its 'normal' behaviour (Teunis et al., 2004). Keeping in mind that quantitative risk assessment not only connects causes and consequences but even attempts to quantify the relation between exposure and health effects, animal challenge studies are not particularly well suited to provide information on dose-response in humans. Furthermore, in a few instances where there are both animal and human infectivity data, there does not seem to be agreement. For example, data from immuno-deficient mice and human volunteers for Cryptosporidium showed surprising similarities (Teunis et al., 2002b; Yang et al., 2000 ), while data from rabbits and human outbreaks of pathogenic $E$. coli showed very little agreement (Haas et al., 2000; Teunis et al., 2004).

\section{Information from outbreak investigations}

Recent studies have attempted to use outbreak investigations as a source of doseresponse information (DuPont et al., 1995; Navarro et al., 2009). Not many outbreaks have been documented sufficiently well to support such analysis, because not only must the exposed and affected (ill, infected) population be known, but also there has to be some knowledge of exposure. For a small subset of all reported outbreaks, this information is available, and a novel form of meta-analysis can be done. Even a single outbreak may provide useful information (Teunis et al., 2004, 2005). A dose-response assessment using several different outbreaks needs to take into account additional levels of variation between outbreaks (Takumi et al., 2009; Teunis et al., 2008). A multi-level dose-response model is best suited for describing such data and can account for differences in exposure conditions and differences in the intrinsic properties of pathogens and hosts.

\section{EXAMPLES OF DOSE-RESPONSE INFORMATION ON SELECTED ENTERIC PATHOGENS}

\section{Norovirus}

Noroviruses are probably the most common cause of epidemic non-bacterial acute gastroenteritis and can be transmitted by faecal-contaminated food, water, 
surfaces and hands. Noroviruses are pathogens of particular concern for produce quality. Several multi-country outbreaks of norovirus associated with raspberries from China or Eastern Europe that were irrigated with contaminated agricultural waters have been described (Hjertqvist et al., 2006). Many norovirus outbreaks have been associated with salads and cut fruits (Gallimore et al., 2005; Herwaldt et al., 1994). Most of these outbreaks have been attributed to produce contamination from contact with infected food-handlers, but it is possible that some of these outbreaks may also have been due to produce that became contaminated in the field or during harvest and transport. Evidence from outbreaks suggests that these viruses are quite persistent in the environment and highly infectious.

The infectivity of Norwalk virus, a prototype norovirus, was examined in a series of human challenge studies (Teunis et al., 2008a). Data from these studies were used to construct a dose-response model (Figure 4.1). A single hit model for microbial infection was adjusted for virus aggregation by performing a joint analysis of challenge studies with aggregated and disaggregated virus inocula. The model parameters (alpha, beta) describe a beta distribution of the single unit (virion) infectivity and indicate that Norwalk virus is the most infectious agent ever described. The median infectious dose was estimated to be 18 virus genome copies (as measured by quantitative real-time reverse transcription-polymerase chain reaction), and the virus was highly infectious at low doses (average probability of infection of about 50 per cent for a single virus genome), which is especially relevant for environmental contamination of produce. In addition, these challenge studies revealed differences in host susceptibility and possible protective immunity through a mucosal immune response (Lindesmith et al., 2003). At the highest doses tested, the infection rate seemed to level off at about 75 per cent (Figures $4.1 \mathrm{a}$ and $4.1 \mathrm{~b}$ ), suggesting that some proportion of the population may be protected from infection.

\section{E. coli 0157:H7}

E. coli $\mathrm{O} 157: \mathrm{H} 7$ has also been associated with a number of outbreaks from contaminated produce. In 2006, a large, multi-state outbreak of E. coli O157: $\mathrm{H} 7$ in the USA was linked to the consumption of fresh spinach and involved over 200 laboratory-confirmed cases (Wendel et al., 2009). The dose-response model for E. coli O157:H7 (Figure 4.2) shows that the infectivity of this pathogen shows considerable variation between outbreaks, but it is likely to be high (about 1 per cent probability of infection for a single colony-forming unit). Exposure to even low doses of E. coli $\mathrm{O} 157: \mathrm{H} 7$ is associated with unacceptably high risks of infection and acute diarrhoeal illness (Teunis et al., 2008b). Since such infection also may lead to severe sequelae, such as hemolytic uremic syndrome (HUS), especially in children, the presence of this pathogen must be considered a serious risk at all times. 


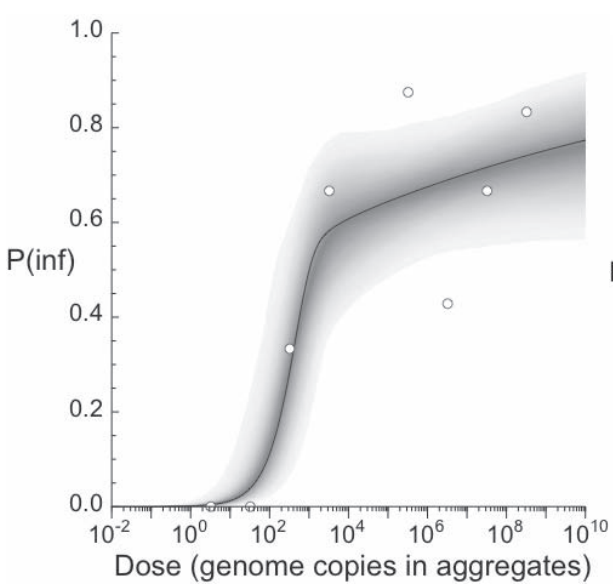

(a)

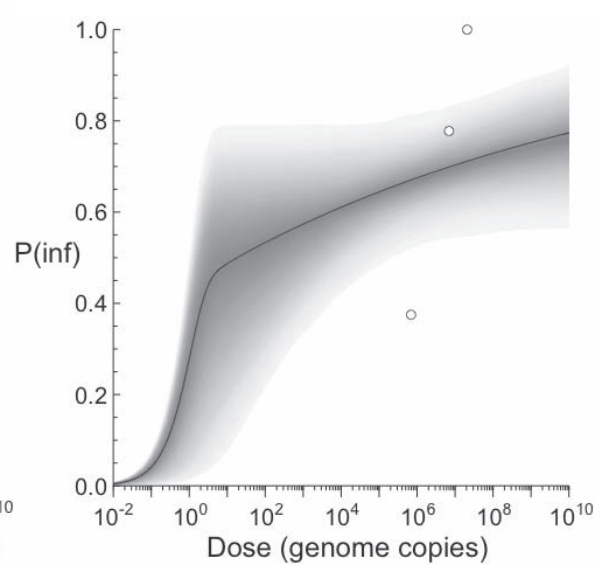

(b)

Figure 4.1 Dose-response relation for infection by Norwalk virus in human challenge study. Model jointly fitted to (a) aggregate primary inoculum and (b) dispersed secondary inoculum, obtained from a volunteer infected with the primary inoculum. Graphs show observed fractions infected, best-fitting dose-response relation and uncertainty in predicted infection probabilities 'P(inf)', as density

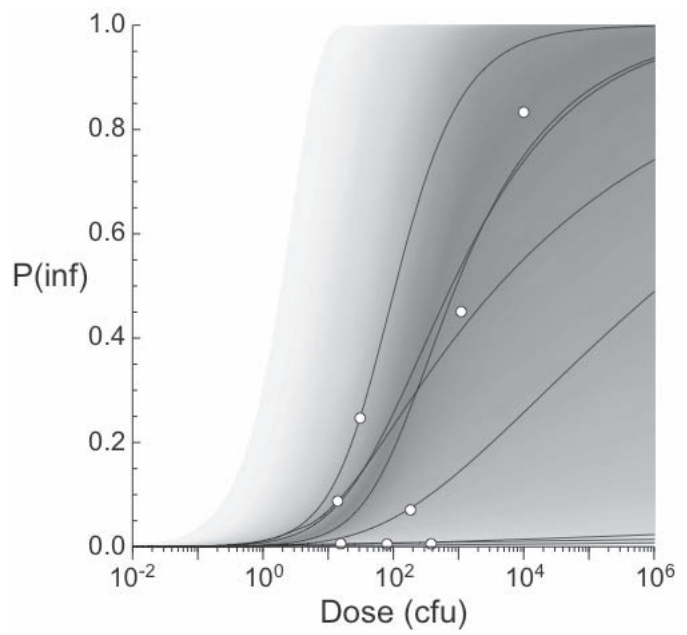

Figure 4.2 Dose-response relation for $\mathrm{E}$. coli O157:H7 based on eight different outbreaks, using a two-level dose-response model, allowing for variation between outbreaks 
A single hit model for microbial infection was adjusted for uncertainty due to heterogeneity in the exposure encountered in the outbreaks. The model was analysed in a hierarchical (two-level) framework to allow for variation within and between outbreaks and to predict the infectivity of this pathogen by generalizing among all included outbreaks. Predicted infectivity was expressed as a beta-distributed single unit infectivity, with parameters (alpha, beta). Figure 4.2 indicates the observed fractions infected; the best-fitting dose-response relations for each outbreak; and the uncertainty in predicted infection probabilities (as density).

\section{Protozoa}

Examples of infection models for Giardia and Cryptosporidium that have been applied in industrialized countries may be found in Rose et al. (1991) and Teunis et al. (2002a, 2002b). The prevalence of giardiasis typically ranges between 2 and 5 per cent of people in industrialized nations (Farthing, 1993). In developing countries, giardiasis prevalence can be as high as 20-30 per cent (Medicine Health, 2009) and few studies have been performed to quantify its risks, particularly compared to Cryptosporidium. Thus, considering the importance of Giardia in public health for developing nations, QMRA applications are illustrated, taking into account that: the health response in each country may be different as some infections may be endemic, and people can develop immunity; and exposure to pathogens can vary considerably at a local level, therefore exposure may be notably different between industrialized and developing countries (Jiménez, 2003; Jiménez and Wang, 2006).

\section{Protozoa risks and reuse practice}

Both Cryptosporidium and Giardia are frequently reported in association with waterborne diseases and have caused many outbreaks around the world, because of their high infectivity (Isaac-Renton et al., 1994) and resistance to chemical disinfection (Finch et al., 1994; Rennecker et al., 1999). Conventional wastewater treatment is known to reduce the numbers of Cryptosporidium oocysts and Giardia cysts by an average of 99.950 per cent (3.17 log reduction) and 99.993 per cent (4.14 log reduction), respectively (Rose et al., 1996). Even so, these protozoan parasites are often detected in tertiary-treated effluents (Gennaccaro et al., 2003; Quintero-Betancourt et al., 2003; Ryu, 2003). This is the reason why risk assessment focuses on evaluating the occurrence of Giardia and Cryptosporidium in source waters, in order to determine the appropriate treatment needed to obtain specific safety levels for drinking water. In addition, both pathogens are commonly recognized causes of recreational waterborne disease (Slifko et al., 2000). Most recreational water outbreaks are the result of faecal accidents or cross-connections in swimming pools. However, the contamination of natural recreational waters with 
animal wastes is not well documented or recognized (Gerba and Gerba, 1995). Outbreaks of foodborne giardiasis and Cryptosporidium have also been reported (Insulander et al., 2008; Rose and Slifko, 1999).

Historically, reclaimed water has been used for agricultural applications, such as pasture irrigation or non-food crop irrigation, and has often been perceived as a method of wastewater disposal. The trend has now shifted towards unconventional reclaimed water uses, such as urban horticultural irrigation, toilet and urinal flushing, commercial and industrial uses, and indirect potable reuse (United States Environmental Protection Agency (USEPA), 2004). However, concerns about the microbial quality of reclaimed water and the potential associated health risks limit its widespread use.

A review of health risks for different groups associated with the use of wastewater in irrigation indicated that no direct evidence of disease transmission was found for exposed groups of consumers, although there was evidence of the occurrence of protozoa on wastewater-irrigated vegetable surfaces (Carr et al., 2004). For farm workers and their families, the risk of Giardia intestinalis infection was found to be insignificant for contact with both untreated and treated wastewater, but an increased risk of amoebiasis was associated with contact with untreated wastewater. For nearby communities, there was no data on the transmission of protozoan infections from sprinkler irrigation with wastewater, and the risk could not be evaluated (Armon et al., 2002; Blumenthal et al., 2000; Blumenthal and Peasey, 2002).

Risks of infection with Giardia spp. and Cryptosporidium parvum in industrialized countries have been associated with drinking water, but never with the use of recycled water (Asano, 1998). However, problems with wastewater reuse have been reported in developing countries where there is evidence of increased risk of Giardia infection, for example, in an agricultural population in Mexico (Cifuentes et al., 2000), in the Jordan Valley (Mutaz, 2007) and in Asnara, Eritrea (Srikanth and Naik, 2004).

The occurrence of Cryptosporidium oocysts and Giardia cysts in reclaimed water and assessment of the risks associated with these protozoan parasites have not been well documented (Gennaccaro et al., 2003; Jolis et al., 1999; QuinteroBetancourt et al., 2003). While substantial efforts are ongoing to improve risk assessment for Cryptosporidium, due to the well-established hazards for immunocompromised subjects, little risk assessment data are available for Giardia (ZmirouNavier et al., 2006).

\section{Dose-response model for Giardia lamblia}

Data on infectious doses shows a considerable difference reported by different authors for the same type of micro-organisms. For Giardia lamblia, Feachem et al. (1983) reported 19 cysts, and Kadlec and Knight (1996) later reported between 25 
and 100 cysts. However, Giardia species/strains are known to have a low infectious dose (Cooper and Olivieri, 1998). Studies on human volunteers performed 40 years ago revealed a dose-response relationship between the probability of infection (as measured by faecal excretion) and the ingested dose of Giardia lamblia (Rendtorff, 1954). The minimum ingestion dose found to be capable of initiating infection in two volunteers (100 per cent) was only ten cysts, but neither of the infected volunteers developed gastrointestinal symptoms.

The dose-response model for assessing the probability of infection from ingestion of Giardia lamblia cysts is an exponential equation (Rose et al., 1991) based on experimental data developed by Rendtorff (1954):

$$
\mathrm{P}=1-\exp (-\mathrm{rN})
$$

$\mathrm{P}$ is the individual daily probability of infection, $\mathrm{r}$ is an organism-specific infectivity parameter, and $\mathrm{N}$ is the daily ingested dose of parasites. The best-fit $\mathrm{r}$ value for Giardia is 0.0199 (95 per cent CI (confidence interval): 0.0044-0.0566) (Rose et al., 1991). The same exponential model applies for Cryptosporidium parvum with $\mathrm{r}=0.0042$ (DuPont et al., 1995) using data from a human challenge study.

\section{Quantitative microbial risk assessment examples for Giardia lamblia}

The most common application of the exponential dose-response model for Giardia has been for QMRA for drinking water, to define the water treatment needed to reduce the risk of waterborne giardiasis (Regli et al., 1991; Teunis et al., 1997; Zmirou-Navier et al., 2006). Fewer applications may be found for risks of giardiasis from wastewater, sludge or faecal excreta reuse (Schönning et al., 2007). Most of these were performed in industrialized rather than developing countries. One example is an epidemiology and microbial risk assessment study (Zmirou-Navier et al., 2006), carried out in southeast France, where the dose-response function derived from epidemiological data was consistent with estimates of infectious risks predicted by the dose-response curve established by Rendtorff (1954). Another study (Regli et al., 1991) gives a detailed description of how risk assessment can be used as an approach for determining what level of water treatment and Giardia reduction is necessary to ensure that the risk of Giardia from treated drinking water is less than 1 infection per 10,000 people per year.

Another example that details efforts to improve risk assessment for Giardia infection is the research of Teunis et al. (1997). Each of the factors contributing to quantitative risk assessment for Giardia lamblia was treated as a stochastic variable, for which a suitable distribution was proposed to analyse the uncertainty in the risk of infection estimations. It was found that the major contributing factors are: the concentration of cysts in raw water; the recovery efficiency of the detection method; 
the viability of recovered cysts; the removal of organisms in the treatment process; and the daily consumption of unboiled tap water. In this study, the calculation of the risk of infection due to exposure to Giardia cysts in drinking water from a surface-water supply in The Netherlands showed that the uncertainty in the estimated removal efficiency of the treatment process dominates the uncertainties due to other contributing factors.

A further example is the work of a Canadian research programme (Saint Lawrence Vision, 2000), which quantified the risk of waterborne Giardia (and also Cryptosporidium) in 45 drinking-water treatment plants. A Monte Carlo model was developed (Barbeau et al., 2000) using a distribution of $\mathrm{r}$ parameter values, that was constructed using 1000 bootstrap replications of the original data from Rendtorff et al. (1954), as described elsewhere (Haas et al., 1996, 1999).

The potential risk of Giardia associated with the use of reclaimed wastewater was assessed by Ryu et al. (2007) for three exposure scenarios: landscape irrigation for golf courses; playgrounds; and recreational compounds. In this study, a relatively low risk of Giardia infection was estimated from exposure to the tertiary-treated effluents from seven reclaimed water treatment plants, located in the southwestern USA, where dual disinfection practices - chlorination and ultraviolet disinfection - demonstrated better reduction of this parasite.

An example of QMRA and hazard analysis and critical control points (HACCP) was applied to a wastewater tertiary treatment plant in the city of Hässleholm, Sweden (see Westrell et al., 2004). Here, primary and biological sludge (dewatered and anaerobically digested) is stored outside the wastewater treatment plant before its reuse on agricultural land. The risk of infection from Giardia, as part of a wider list of pathogens selected for control purposes, was estimated. The human exposure scenarios considered were during treatment, handling, soil application and raw crop consumption, and via water at a wetland area and recreational swimming. It was found that the consumption of vegetables grown in sludge-amended soil presented a lower risk and resulted in a lower number of yearly infections $\left(2 \times 10^{-3}\right.$ median risk per year) than expected. However, the authors pointed out that a significantly higher risk would result if the organisms occurred in higher concentrations in lumps of sludge rather than being homogeneously distributed as assumed. It must also be taken into consideration that current Swedish regulations require a ten-month interval between sludge fertilization and harvesting of crops for raw consumption. However, in this study, a worst case scenario assuming only a onemonth interval was applied.

\section{Issues regarding dose-response}

The Giardia dose-response relationship defined by Rendtorff (1954) has been applied in many risk-assessment studies since 1990. These studies used the exponential dose-response model to estimate risks of giardiasis from a variety of 
different exposure routes and reveal the breadth of experience gained from its application for risk assessment.

One concern is about the ratio of asymptomatic to symptomatic Giardia infections, because in Rendtorff's experiments positive response was measured by cyst excretion, but illness was not determined. Infection with Giardia is usually asymptomatic in humans (Benenson, 1990; Farthing, 1994), with around 39 per cent of the Giardia infections in children less than five years of age and 76 per cent of the Giardia infections in adults having no symptoms. Symptomatic infections, however, have been reported at a rate of 50-67 per cent and as high as 91 per cent, while chronic giardiasis may also develop in as much as 58 per cent of the population infected (Rose et al., 1991). Moreover, there is evidence that there may be some degree of population immunity, associated with exposure to Giardia cysts in drinking water (Roxstrom-Lindquist et al., 2006). Thus, the illness to infection ratio is highly variable (Nash et al., 1987) and risk estimates based on infection as an endpoint may overestimate the number of cases of illness.

Another important issue regarding the dose-response curve based on the Rendtorff data is uncertainty about differences in infectivity due to strain variation and the immune response to infection by different populations. The Rendtorff data are derived from a single Giardia lamblia strain and a relatively small sample population of adults. Hence, variability related to infectivity of different strains and to the immune response of hosts cannot be addressed (Zmirou-Navier et al., 2006). The confidence interval for the probability of infection at a specific dose does not take these uncertainties into account when using the model as a predictive tool. Thus, these limitations must be taken into account in risk-assessment studies (Rose et al., 1991).

Assuming the dose-response relationship derived from the Rendtorff data is representative, we may be overestimating giardiasis risks if we assume that all Giardia cysts detected in water are viable and are species that infect humans (Rose et al., 1991). To date, there are no data on the viability of Giardia cysts detected in reclaimed water (Ryu et al., 2007). On the other hand, the underestimation of risk may be of greater concern due to underestimation of exposure by the inefficiencies of the methods to concentrate and detect Giardia cysts in water. In spite of its limitations, the dose-response model for Giardia can be helpful for interpreting data from waterborne disease outbreaks and disease surveillance data associated with various exposure routes (Rose et al., 1991).

The current dose-response information for Giardia is based on healthy adult hosts. From a public-health perspective, this is not the most important group. Compared to newborns, elderly persons and other risk groups, the estimated risks of infection using these data may be an underestimation for some subgroups of the population (Teunis et al., 1997). Other factors, such as nutritional status, predisposing illness and previous exposure will also play a role in determining susceptibility to infection and the outcome of an infection (Flannagan, 1992). 


\section{Helminth eggs}

As described in Chapter 2, helminthiases diseases are frequently linked to the use of wastewater, sludge or excreta in agriculture. Helminthiases are transmitted through the ingestion of helminth eggs which are the ova of a wide variety of pathogenic worms (Jiménez, 2009) and are considered to be the most resistant biological particles in the field of environmental engineering. The occurrence of helminth eggs in wastewater and sludge in developing countries differs considerably from that of industrialized countries because of the much lower prevalence of these infections in the latter (Jiménez, 2009). The presence of helminth eggs in wastewater or sludge cannot be inferred from the presence or concentration of faecal coliforms that are just bacterial indicators of faecal contamination. Additionally, faecal coliforms behave differently than helminth ova in conventional disinfection systems. For example, helminth eggs cannot be inactivated with chlorine, UV light or ozone (Jiménez, 2007). Differences in health conditions (Table 4.1) mean that the helminth ova $(\mathrm{HO})$ content in wastewater and sludge can be 7-80 times greater in developing countries relative to developed ones.

WHO (2006) has set a limit surveillance criterion of $\leq 1 \mathrm{HO}$ per litre for wastewater used for irrigation. In faecal sludge, WHO suggests a limit of $1 \mathrm{HO}$ $\mathrm{g}^{-1}$ TS (TS: total solids). These values were established based on epidemiological evidence and not by using risk-assessment approaches (Navarro et al., 2009). Unfortunately, considering the high initial helminth egg concentrations present in wastewater and sludge in many developing countries, these criteria require very high efficiencies in treatment methods $(<99$ per cent) that are often unaffordable. Thus, there is a need to determine whether these values are really necessary to protect human health and also how efficient other intervention methods, such as washing produce, are. For all these reasons, it is important to estimate the risk, and to achieve this, a dose-infection curve is needed.

\section{Examples of dose-response and QMRAs applied to helminth eggs}

In developing countries, it is difficult to obtain outbreak data. This is due to the endemic nature of helminth infections, such as Ascariasis, Trichuriasis and Schistosomiasis, the number of sources of infection and the delays observed between exposure to the pathogen and symptomatic response. Despite these limitations, a QMRA analysis was performed using a dose-response curve developed by Navarro et al. (2009), with information available from three previous studies. The first was an epidemiological study establishing the prevalence of Ascaris lumbricoides in the Mezquital Valley, Mexico (Blumenthal et al., 1996; Cifuentes et al., 1991, 1993). The second source of data was a wastewater-quality study assessing the occurrence of $A$. lumbricoides in the wastewater used to irrigate the valley (Jiménez et al., 
Table 4.1 Helminth ova (HO) content in wastewater and sludge from different countries

\begin{tabular}{lcc}
\hline Country or region & Municipal wastewater $\mathrm{HO} \mathrm{I}^{-1}$ & Sludge $\mathrm{HO} \mathrm{g}^{-1} \mathrm{TS}^{-1}$ \\
\hline Developing countries & $70-3000$ & $70-735$ \\
Brazil & $166-202$ & 75 \\
Egypt & No data & Mean: $67 ;$ \\
& & maximum: 735 \\
Ghana & No data & 76 \\
Jordan & 300 & No data \\
Mexico & $6-98$ in cities & $73-177$ \\
& 840 & \\
Morocco & 60 & No data \\
Ukraine & 9 & No data \\
France & Up to 330 in rural and peri-urban areas & $5-7$ \\
Germany & No data & $<1$ \\
Great Britain & No data & $<6$ \\
United States & $1-8$ & $2-13$ \\
\hline
\end{tabular}

Source: Jiménez (2009)

1992). The third study consisted of experimental research on the occurrence of $A$. lumbricoides in crops grown in biosolids-enriched soil (Jiménez et al., 2006).

\section{Ascaris lumbricoides dose-response}

The data from these studies was used to develop a dose-response relationship for exposure to $A$. lumbricoides through ingestion of raw crops irrigated with wastewater. The population of concern was children of less than 15 years of age from different communities in the Mezquital Valley (3,346 population sample size). This is the most vulnerable group in the valley, with the highest annual $A$. lumbricoides prevalence rate of between 10 and 17 per cent (Blumenthal et al., 1996; Cifuentes et al., 1991, 1993). This group is exposed to different helminth ova concentrations on crops because the quality of the wastewater used for irrigation varies through the valley as a consequence of sedimentation in several reservoirs. This variation (33 to $73 \mathrm{~A}$. lumbricoides ova/ $/ 5$ litres of wastewater) was characterized from data measured across the irrigation channels in the valley, taking into account the variation in the viability of the ova (52-93 per cent). In addition, some assumptions were made in estimating the exposure dose; it was assumed that $10 \mathrm{ml}$ of wastewater remains (Shuval et al., 1997) in each $100 \mathrm{~g}$ of produce eaten raw such that the Ascaris levels on crops varied from 0.42 to 1.15 Ascaris per $100 \mathrm{ml}$ of water in the crop. Ingestion of $100 \mathrm{~g}$ of raw crops per week during a year was assumed as a reasonable mean consumption for a child.

The best-fit dose-response relationship for the epidemiological data, following the procedure of Haas et al. (1999), was a beta-Poisson model (alpha $=0.104$ beta 
$=1.096$ ) to estimate risk of $A$. lumbricoides infection for a child who consumes raw crops once per week during a year. A detailed description of the estimates may be found in Navarro et al. (2009).

$$
P(d)=1-\left(1+\frac{d}{1.1}\right)^{-0.104}
$$

This dose-response relationship focuses on infection prevalence rather than on illness or disease. It applies only for A. lumbricoides infection in a typical Mexican wastewater irrigation scenario, but may not be representative for other common helminthiases in developing countries with different infectivity and severity of illness (Jiménez, 2007). Thus, this method should be replicated in other developing countries to fit the dose-response relationship to their local scenarios. Recognizing that there are several sources of uncertainty in the model proposed, some improvements may be considered depending on the availability of data. For example, appropriate data for the specific study region regarding types of crops, ranges of pathogen levels in wastewater, estimates of the amount of wastewater remaining on the crop, range of typical crop consumption and frequency, are needed to reduce uncertainties; furthermore, the use of probability distributions to describe model variables will improve the confidence of infection predictions.

\section{QMRA for Ascaris lumbricoides}

The results of a QMRA for A. lumbricoides, based on the dose-response developed in the above equation, are presented to analyse the potential risks from agricultural wastewater and sludge reuse in developing countries, and to develop feasible, riskbased limits on helminth ova on wastewater and sludge rather than criteria based on limited epidemiological data and efficiencies of treatment processes. Two scenarios were considered to illustrate how safety criteria may be estimated applying QMRA: consumption of raw spinach irrigated with untreated wastewater; and consumption of raw spinach and carrots grown in biosolids-amended soil.

The available data on the quality of wastewater used for irrigation, the quantity of wastewater remaining in crops, as well as the population of concern (children under 15 years of age) and the exposure frequency (once per week during a year) used for the development of the dose-response were considered. Additionally, data on child ingestion rates (IR) for each vegetable ( $\left(\mathrm{R}_{\text {carrot }}, \mathrm{IR}_{\text {spinach }}\right)$ available in an international database (USEPA, 1997 and 2002) were assumed for QMRA, rather than a point estimation of $100 \mathrm{~g} / \mathrm{d}$ that was used previously. These new data sources and assumptions improve the risk estimation and allow analysis of the exposure variability. A detailed description of the exposure dose estimations and risk calculations may be found in Navarro et al. (2009) and in Jiménez and Navarro (2009). 


\section{Infection risk from eating raw vegetables irrigated with untreated wastewater}

The annual expected risk of $A$. lumbricoides infection associated with a single week of exposure to wastewater-irrigated spinach eaten raw after harvesting, estimated with the beta-Poisson model, varied from $5 \times 10^{-2}$ to $9 \times 10^{-1}$ per child per year. This estimate implies an infection rate of 5 per cent to 89 per cent in the exposed population after one year and illustrates a worst case scenario where no hygiene measures were assumed.

If a washing procedure is added after harvesting (for example, with weak detergent solution and rising thoroughly with safe drinking water) and reduces the Ascaris ova concentration by $1 \log _{10}$ (WHO, 2006), the risk estimates for Ascaris infection are reduced by two orders of magnitude (between $5 \times 10^{-3}$ to 2.5 $\times 10^{-1}$ per child per year). The expected infection rate would be less than 17 per cent per year, except for when the maximum values for Ascaris levels in irrigation wastewater (115 Ascaris ova/5 litres) and for consumption $(270 \mathrm{~g} / \mathrm{d})$ are assumed (Figure 4.3).

Infection incidence of less than 3 per cent might occur if efficiencies of the washing procedure were further improved resulting in a $2 \log$ reduction in Ascaris exposure (between $6 \times 10^{-4}$ to $2.7 \times 10^{-2}$ per child per year).

These results show that risk of Ascaris infection depends on the concentration of the pathogen in the wastewater and the application rate on the crops $\left(\mathrm{C}_{\text {Ascaris }}\right)$, as well as the quantity of potentially contaminated crops that are consumed $\left(\operatorname{IR}_{\text {spinach }}\right)$. We demonstrate how the risk of infection could be reduced if improved washing of the harvested produce is practised.

Thus, considering those factors that influence the health-risk estimates, even though the overall risk of infection may be greater than $10^{-4}\left(6 \times 10^{-4}\right.$ to $3 \times 10^{-2}$ per child per year), a less risky and feasible application of wastewater for irrigation in the region may be achieved if $\mathrm{C}_{\text {Ascaris }} \leq 115$ Ascaris lumbricoides ova/5 litres (equivalent to 23 viable Ascaris ova per litre) is used for irrigation. This level of health protection may well be reinforced with intervention methods that include sanitary campaigns to improve harvesting and both commercial and consumers' washing procedures, among other practices.

\section{Infection risk from eating raw vegetables grown in biosolids- amended soil}

In order to estimate the risk of eating raw vegetables grown in soil fertilized with biosolids $(0.25,1,4$ and $37 \mathrm{HO} / \mathrm{gTS})$, the results from an experimental study were used to estimate the number of pathogens on the crop, assuming that $A$. lumbricoides accounted for 90 per cent of the total helminth ova $(\mathrm{HO} / \mathrm{g})$ content in spinach (6.5-305 Ascaris $/ 100 \mathrm{~g}$ ) and carrots (0.3-49 Ascaris/100g). A detailed description of the data is published elsewhere (Jiménez et al., 2006). 


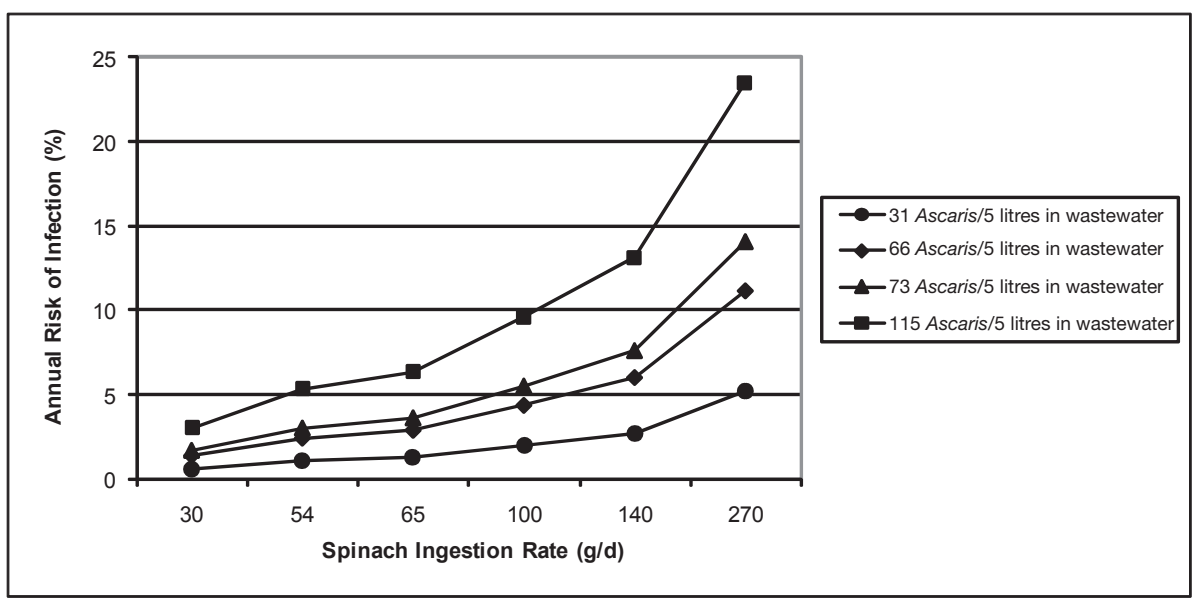

Figure 4.3 Risk estimate from annual exposure to spinach irrigated with four different Ascaris concentrations in wastewater for several consumption rates

Source: Based on Jiménez and Navarro (2009)

The annual risk of consuming uncooked spinach grown on biosolids-amended soil, after harvesting, without any intervention method, was estimated to be 1 infection per child per year. In this case, unlike the estimated risks associated with wastewater irrigation, the estimated infection rates were similar to the ascariasis incidence rate observed in the region (< 17 per cent) - assuming the USEPA (1993) criterion of $\mathrm{HO} / 4 \mathrm{gTS}$ equivalent to $0.25 \mathrm{HO} / \mathrm{gTS}$ for the biosolids and a washing procedure that provides a $2 \log _{10}$ reduction in $A$. lumbricoides ova concentration on the spinach (Figure 4.4). This applies to a spinach consumption rate by children of $\leq$ $65 \mathrm{~g} / \mathrm{d}$ once per week during a year. The $0.25 \mathrm{HO} / \mathrm{gTS}$ criterion for biosolids is a restrictive limit for developing countries where it is difficult to reduce the typically high $\mathrm{HO}$ content in sludge to such low levels.

A comparative QMRA for spinach and carrots grown on biosolids-amended soil (Navarro et al., 2009) illustrates that the health risk is also a function of the type of crop. These results indicated that the annual risk $\left(4.5 \times 10^{-3}\right.$ to $9.6 \times 10^{-1}$ Ascaris infections per child per year) from raw carrot ingestion is less than the annual risk associated with spinach consumption. In fact, an initial limit for the region, with annual infection rates expected $<22$ per cent, may be set at $4 \mathrm{HO} /$ gTS content in biosolids for a reasonable carrot mean consumption rate $\leq 100 \mathrm{~g} / \mathrm{d}$ once per week during a year (Figure 4.5). This situation, although not ideal, would turn out to be an acceptable safety limit with gradual reductions that progressively improve local health, social and economic conditions, since this limit is feasible in developing countries. 


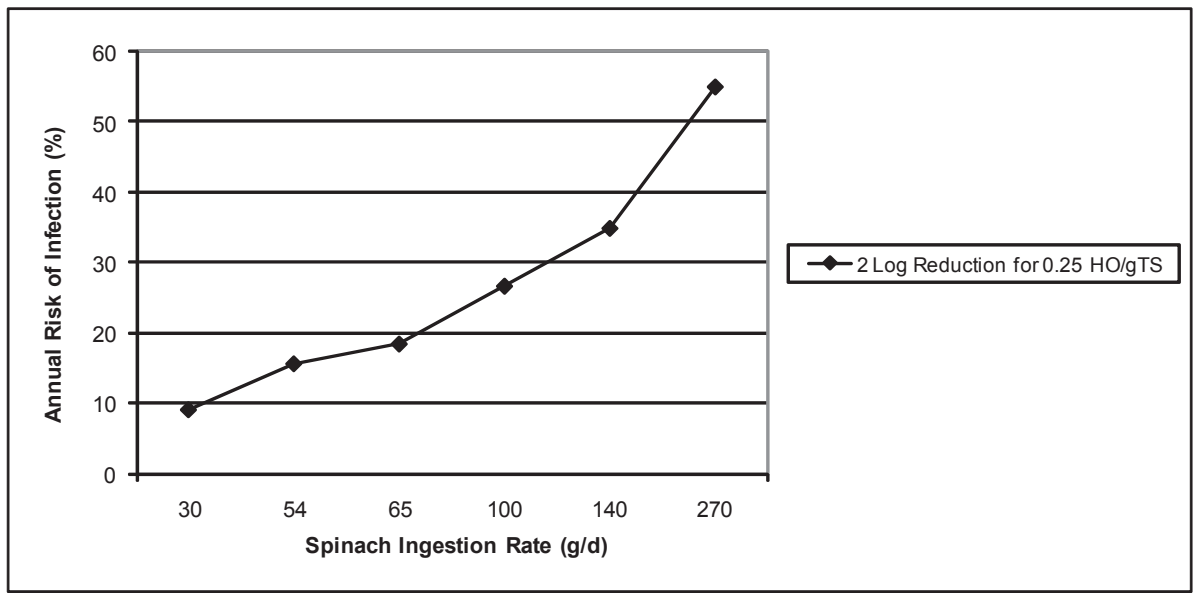

Figure 4.4 Estimated annual risk of Ascaris infection associated with exposure to spinach grown on biosolids-amended soil

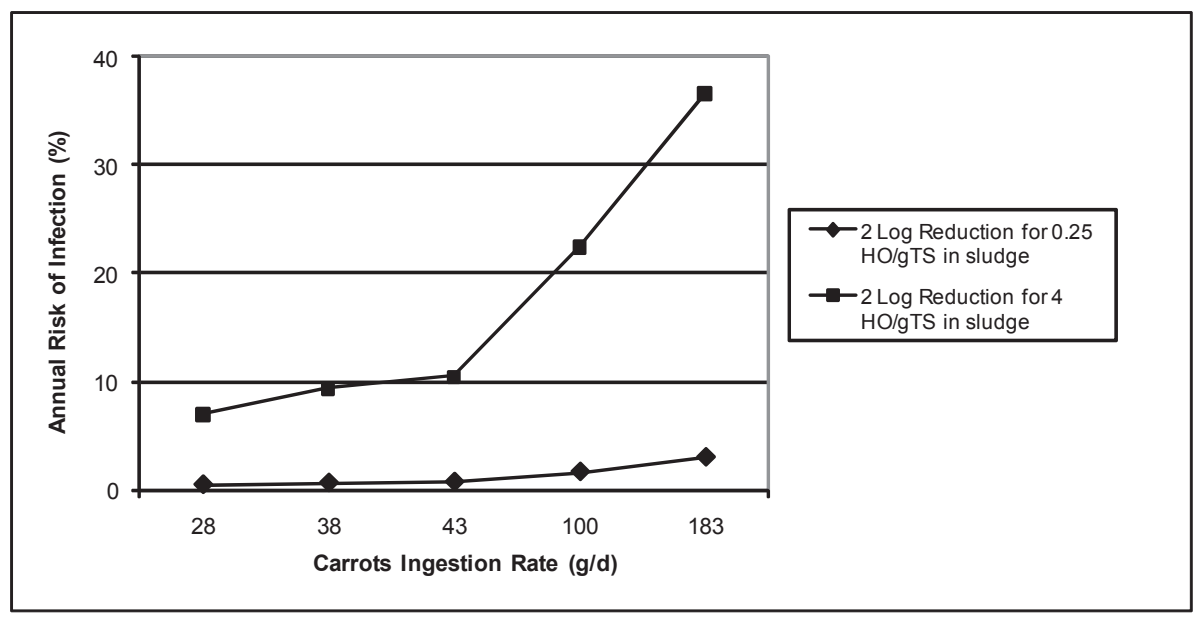

Figure 4.5 Estimated annual risk of Ascaris infection associated with exposure to carrots grown on biosolids-amended soil

Source: Based on Navarro et al. (2009)

These real scenarios illustrate a QMRA approach for examining the risks of Ascaris infection associated with crops that are either irrigated with wastewater or grown in soil that has been amended with faecal sludge. These analyses indicate that differences in the level of exposure to pathogenic organisms may arise from 
variations in $\mathrm{HO}$ concentrations in vegetables and in consumption patterns. To improve confidence in the estimated risks predicted by these analyses, those factors contributing to increased variability need to be better characterized in order to develop safe and feasible HO limits for wastewater and biosolids that are applied in food-crop production in developing countries. Other factors influencing HO concentrations in vegetables include irrigation practices, differences between ova accumulation on root or non-root crops, excreta application rates and efficacy of ova reduction during produce-washing. Therefore, the actual occurrence and concentration of $A$. lumbricoides in food crops will improve confidence in the risk estimation.

\section{HELMINTH OVA STANDARDS FOR DEVELOPING COUNTRIES}

The analyses presented above suggest that WHO guideline limits for wastewater and sludge reuse in agricultural production may be too restrictive for developing countries. These findings illustrate that recommended thresholds for $\mathrm{HO}$ concentrations in wastewater and biosolids could be raised by an order of magnitude for some settings and would not significantly increase the risk of Ascaris infection above current endemic rates. Although higher Ascaris infection rates would be predicted by a change in the thresholds and the risk estimates are greater than $10^{-4}$ per child per year, changing the $\mathrm{HO}$ standards to those that predict infection rates that are still less than the local endemic prevalence may induce a gradual improvement in population health conditions. Finally, limits on pathogen concentrations in wastewater and biosolids used for irrigation or fertilization should be implemented in an integrated framework for risk management where other sources of helminth exposure and the impact of additional health-protection measures, such as improvements in the washing of produce, may be considered.

\section{Conclusions}

\section{Application of microbial risk assessment approaches}

As presented here, it is feasible to examine the potential risks of infection associated with the consumption of food crops that are irrigated with wastewater or fertilized with biosolids using a QMRA approach. The application of QMRA to this situation requires information on pathogen dose-infection relationships, transmission pathways, occurrence (frequency and concentration) of pathogens in wastewater and biosolids, persistence of pathogen viability or infectivity in the environment and on the food crops and crop consumption (amount and frequency). This approach allows the exploration of various 'what if' scenarios that can include interventions to reduce exposure - such as treatment of the wastewater or biosolids or washing the produce. 
However, assessment of the risks associated with ingestion of food crops irrigated or fertilized with wastewater, biosolids or faecal sludge should consider the local context of likely exposure routes, pathogen occurrence and concentration in wastewater and biosolids, and endemic disease rates. The availability of local data for these inputs into the risk-assessment model may be very limited or nonexistent, especially in developing countries.

\section{Estimating exposure}

Pathogens are rarely measured in environmental samples (wastewater, biosolids, faecal sludge, soils and crops) because of the laboratory resources required for these analyses. Data from microbial indicator organisms (such as E. coli or coliphage) may be easier to collect in developing countries and may provide some indication of the magnitude of pathogen concentrations in wastewater or biosolids or on produce (Salgot et al., 2006). Similarly, the measurement of microbial indicator organisms may also provide information on the magnitude of microbial reduction that occurs from specific interventions, such as washing produce or changing irrigation methods. The use and choice of microbial indicators for waterborne pathogens has been extensively reviewed by the National Research Council (2004). However, for helminths there is no alternative indicator.

\section{Estimating dose-response}

Dose-response information is a critical component of microbial risk assessment. As described in this chapter, dose-response data are not available for all the pathogens of interest and there are several sources of uncertainty in existing dose-response data. Dose-response information often comes from studies conducted on healthy adults in industrialized countries and may not reflect the response of vulnerable subgroups in the population (young children and the elderly) or populations in developing countries where there may be greater local immunity to specific infections that are endemic. Dose-response data from outbreaks in developing countries is also rare because of the lack of resources for investigations. So, it may not be possible to use this as a source for estimating the dose-response relationship in a developing-country setting. In some settings, data on paediatric diarrhoea or helminth infections may be available from government surveillance systems, government or private health clinics, national demographic and health surveys or from specific research studies. Using QMRA, it may be possible to test the potential appropriateness of different dose-response functions by validating with outbreak data (Haas and Eisenberg, 2001) or comparing predicted risk to actual disease rates reported in surveillance systems or research studies. 


\section{Guidelines for safe use of wastewater, biosolids and faecal sludge for food crops}

Microbial risk assessment can be a tool to test the usefulness of international guidelines and standards for acceptable levels of pathogens in wastewater, biosolids and faecal sludge used in the production of food crops in a defined context that takes into account local exposure routes, local immunity and alternate health risks. QMRA can be used to develop safe, appropriate local guidelines that can be adjusted as agricultural production becomes more advanced and the health and quality of life in the community improves.

\section{REFERENCES}

Armon, R., Gold, D., Brodsky, M. and Oron, G. (2002) 'Surface and subsurface irrigation with effluents of different qualities and presence of Cryptosporidium oocysts in soil and crops', Water Science and Technology, vol 46, no 3, pp 115-22

Asano, T. (1998) Wastewater Reclamation and Reuse, Water Quality Management Library vol 10, Technomic Publishing Inc., Lancaster, PA

Barbeau, B., Payment, P., Coallier, J, Clement, B. and Prévost, M. (2000) 'Evaluating the risk of infection from the presence of Giardia and Cryptosporidium in drinking water', Quantitative Microbiology, vol 2, pp 37-54

Benenson, A. S. (ed) (1990) Control of Communicable Diseases in Man, American Public Health Association, Washington, DC

Blumenthal, U. J., Duncan, M., Ayres, R. M., Cifuentes, E., Peasey, A., Stott, R., Lee, D. L. and Ruiz-Palacios, G. (1996) 'Evaluation of the WHO nematode egg guidelines for restricted and unrestricted irrigation', Water Science and Technology, vol 33, nos 10-11, pp277-83

Blumenthal, U. J., Mara, D. D., Peasey, A., Ruiz-Palacios, G. and Stott, R. (2000) 'Guidelines for the microbiological quality of treated wastewater used in agriculture: Recommendations for revising WHO guidelines', Bulletin of the World Health Organization, vol 78, no 9, pp1104-16

Blumenthal, U. J. and Peasey, A. (2002) 'Critical review of epidemiological evidence of the health effects of wastewater and excreta use in agriculture', unpublished document prepared for World Health Organization, Geneva, www.who.int/water_sanitation_ health/wastewater/whocriticalrev.pdf

Carr, R. M., Blumenthal, U. J. and Mara, D. D. (2004) 'Guidelines for the safe use of wastewater in agriculture: Revisiting WHO guidelines', Water Science and Technology, vol 50, no 2, pp31-8

Chen, L., Geys, H., Cawthraw, S., Havelaar, A. H. and Teunis, P. (2006) 'Dose response for infectivity of several strains of Campylobacter jejuni in chickens', Risk Analysis, vol 26, no 6, pp1613-21

Cifuentes, E., Blumenthal, U., Ruiz-Palacios, G. and Bennett, S. (1991) 'Health impact evaluation of wastewater use in Mexico', Public Health Review, vol 92, no 19, pp24350 
Cifuentes, E., Blumenthal, U., Ruiz-Palacios, G., Bennett, S., Quigley, M. and RomeroAlvarez, H. (1993) 'Problemas de salud asociados al riego agrícola con agua residual en Mexico', Salud Pública de Mexico, vol 35, no 6, pp614-19 (in Spanish)

Cifuentes, E., Gomez, M., Blumenthal, U., Tellez-Rojo, M. M., Romieu, I., RuizPalacios, G. and Ruiz-Velazco, S. (2000) 'Risk factors for Giardia intestinalis infection in agricultural villages practicing wastewater irrigation in Mexico', American Journal of Tropical Medicine Hygiene, vol 62, no 3, pp388-92

Cooper, R. C. and Olivieri, A.W. (1998) 'Infectious disease concerns in wastewater reuse', in T. Asano (ed) Wastewater Reclamation and Reuse, Technomic Publishing Co., Lancaster, PA, pp489-520

DuPont, H. L., Chappel, C. L., Sterling, C. R., Okhuysen, P. C., Rose, J. B. and Jakubowski, W. (1995) 'The infectivity of Cryptosporidium parvum in healthy volunteers', New England Journal of Medicine, vol 332, no 13, pp855-9

Farthing, M. J. G. (1993) 'Diarroeal disease: Current concepts and future challenges, pathogenesis of giardiasis', Transactions of the Royal Society of Tropical Medicine and Hygiene, vol 87, pp17-21

Farthing, M. J. G. (1994) 'Giardiasis as a disease', in R. C. A. Thompson, J. A. Reynoldson and A. J. Lymbery (eds) Giardia: From Molecules to Disease, CABI International, Wallingford, UK, pp15-37

Feachem, R., Bradley, D., Garelick, H. and Mara, D. (1983) Sanitation and Disease: Health Aspects of Excreta and Wastewater Management, John Wiley and Sons, New York

Finch, G. R., Black, E. K., Gyuèreck, L. and Belosevic, M. (1994) Ozone Disinfection of Giardia and Cryptosporidium, American Water Works Association, Denver, CO

Flannagan, P. A. (1992) 'Giardia diagnosis, clinical course and epidemiology - A review', Epidemiology and Infection, vol 109, pp1-22

Gallimore, C. I., Pipkin, C., Shrimpton, H., Green, A. D., Pickford, Y., McCartney, C., Sutherland, G., Brown, D. W. and Gray, J. J. (2005) 'Detection of multiple enteric virus strains within a foodborne outbreak of gastroenteritis: An indication of the source of contamination', Epidemiology Infections, vol 133, no 1, pp41-7

Gennaccaro, A. L., McLaughlin, M. R., Quintero-Betancourt, W., Huffman, D. E. and Rose, J. B. (2003) 'Infectious Cryptosporidium parvum oocysts in final reclaimed effluent', Applied Environmental Microbiology, vol 69, no 8, pp4983-4

Gerba, C. P. and Gerba, P. (1995) 'Outbreaks caused by Giardia and Cryptosporidium associated with swimming pools', Journal of Swimming Pool and Spa Industry, vol 1, pp9-18

Haas, C. N., Crockett, C. S., Rose, J. B., Gerba, C. P. and Fazil, A. M. (1996) 'Assessing the risk posed by (oo)cysts in drinking water', Journal of the American Works Association, vol 88, no 9, p131

Haas, C. and Eisenberg, J. N. S. (2001) 'Risk assessment', in L. Fewtrell and J. Bartram (eds) Water Quality: Guidelines, Standards and Health; Assessment of Risk and Risk Management for Water-Related Infectious Disease, International Water Association (IWA) on behalf of the World Health Organization, London, pp161-83

Haas, C. N., Rose, J. B. and Gerba, C. P. (1999) Quantitative Microbial Risk Assessment, John Wiley and Sons, New York, p464 
Haas, C. N., Thayyar-Madabusi, A., Rose, J. B. and Gerba, C. P. (2000) 'Development of a dose-response relationship for Escherichia coli O157:H7', International Journal of Food Microbiology, vol 57, pp153-9

Herwaldt, B. L., Lew, J. F., Moe, C. F., Lewis, D. C., Humphrey, C. D., Monroe, S. S., Pon, E. W. and Glass, R. I. (1994) 'Characterization of a variant strain of Norwalk virus from a foodborne outbreak of gastroenteritis on a cruise ship in Hawaii', Journal of Clinic Microbiology, vol 32, no 4, pp861-6

Hjertqvist, M., Johansson, A., Svensson, N., Åbom, P. E., Magnusson, C., Olsson, M., Hedlund, K. O. and Andersson, Y. (2006) 'Four outbreaks of norovirus gastroenteritis after consuming raspberries, Sweden', Eurosurveillance, vol 11, no 7, p9

Insulander, M., de Jong, B. and Svenungsson, B. (2008) 'A foodborne outbreak of cryptosporidiosis among guests and staff at a hotel restaurant in Stockholm county, Sweden, September 2008', Eurosurveillance, vol 13, no 51, www.eurosurveillance.org/ ViewArticle.aspx?ArticleId=19071

Isaac-Renton, J. L., Lewis, L. F., Ong, C. S. L. and Nulsen, M. F. (1994) 'A second community outbreak of waterborne giardiasis in Canada and serological investigation of patients', Transactions of the Royal Society of Tropical Medicine and Hygiene, vol 88, no 4, pp395-9

Jiménez, B. (2003) 'Health risks in aquifer recharge with recycle water', in R. Aertgeerts and A. Angelakis (eds) State of the Art Report Health Risk in Aquifer Recharge using Reclaimed Water, WHO Regional Office for Europe, Rome

Jiménez, B. (2007) 'Helminth ova control in sludge: A review', Water Science and Technology, vol 56, no 9, pp147-55

Jiménez, B. (2009) 'Helminth ova control in wastewater and sludge for agricultural reuse', in W.O.K. Grabow (ed) Encyclopaedia of Biological, Physiological and Health Sciences, Water and Health, vol 2, EOLSS Publishers Co Ltd, Oxford, and UNESCO, Paris, pp429-49

Jiménez, B., Austin, A., Cloete, E. and Phasha, C. (2006) 'Using Ecosan sludge for crop production', Water Sciences and Technology, vol 5, no 54, pp169-77

Jiménez, B., Chávez, A. and Maya, C. (1992) 'Characterization of the water and wastewater used to irrigate the Mezquital Valley', Internal Report No 2345, Engineering Institute, UNAM, Mexico. Unpublished manuscript (in Spanish), available upon request

Jiménez, B. and Navarro, I. (2009) 'Methodology to set regulations for safe reuse of wastewater and sludge for agriculture in developing countries based on a scientific approach and following the new WHO Guidelines', in Dr Ashish Dwivedi (ed) Handbook of Research on Information Technology Management and Clinical Data Administration in Healthcare, vol 1, IGI Global, Hershey, New York, pp1027

Jiménez, B. and Wang, L. (2006) 'Sludge treatment and management', in Z. Ujang and M. Henze (eds) Municipal Wastewater Management in Developing Countries: Principles and Engineering, IWA Publishing, London, pp237-92

Jolis, D., Pitt, P. and Hirano, R. (1999) 'Risk assessment for Cryptospridium parvum in reclaimed water', Water Research, vol 33, no 13, pp3051-5

Kadlec, R. and Knight, R. (1996) Treatment Wetlands, CRC Press, Boca Raton, FL, p893

Lindesmith, L., Moe, C., Marionneau, S., Ruvoen, N., Jiang, X., Lindblad, J., Stewart, P., LePendu, J. and Baric, R. (2003) 'Human susceptibility and resistance to Norwalk virus infection', Nature Medicine, vol 9, no 5, pp548-53 
Medicine Health (2009), www.emedicinehealth.com/giardiasis/article_em.htm

Mutaz, Al-Alawi (2007) 'Health assessment of wastewater reuse in Jordan', in Wastewater Reuse - Risk Assessment, Decision-Making and Environmental Security, NATO Security through Science Series, Springer, The Netherlands, pp385-92

Nash, T. E., Herrington, D. A., Losonsky, G. A., Levine, M. and Nash, T. (1987) 'Experimental human infections with Giardia intestinalis', Journal of Infectious Diseases, vol 156, pp 974-84

National Research Council (2004) Indicators for Waterborne Pathogens, National Academies Press, Washington, DC, www.nap.edu/catalog.php?record_id=11010\#toc

Navarro, I., Jiménez, B., Cifuentes, E. and Lucario, S. (2009) 'Application of helminth ova infection dose curve to estimate the risks associated with biosolid application on soil', Journal of Water and Health, vol 7, no 1, pp31-44

Quintero-Betancourt, W., Gennaccaro, A. L., Scott, T. M. and Rose, J. B. (2003) 'Assessment of methods for detection of infectious Cryptosporidium oocysts and Giardia cysts in reclaimed effluents', Applied Environmental Microbiology, vol 69, no 9, pp5380-88

Regli, S., Rose, J. B. and Haas, C. N. (1991) 'Modelling the risk from Giardia and viruses in drinking water', American Water Works Association, vol 83, no 11, pp 76-84

Rendtorff, R. C. (1954) 'The experimental transmission of human intestinal protozoan parasites, 1. Giardia cysts given in capsules', American Journal of Hygiene, vol 59, pp209

Rennecker, J. L., Marinas, B. J., Owens, J. H. and Rice, E. W. (1999) 'Inactivation of Cryptosporidium parvum (oo)cysts with ozone', Water Research, vol 33, p2481

Rose, J. B., Dickson, L. J., Farrah, S. R. and Carnahan, R. P. (1996) 'Removal of pathogenic and indicator microorganisms by a full-scale water reclamation facility', Water Research, vol 30, no 11, pp2785-97

Rose, J. B., Haas, C. N. and Regli, S. (1991) 'Risk assessment and control of waterborne giardiasis', American Journal of Public Health, vol 81, no 6, pp709-13

Rose, J.B. and Slifko, T.R. (1999) 'Giardia, Cyclospora, and Cryptosporidium and their impact on foods: A review', Journal of Food Protection, vol 62, pp1059-70

Roxstrom-Lindquist, K., Palm, D., Reiner, D., Ringqvist, E. and Svard, S. G. (2006) 'Giardia immunity - An update', Trends in Parasitology, vol 2, no 1, pp26-31

Ryu, H. (2003) 'Microbial quality and risk assessment in various water cycles in the southwestern United States', PhD dissertation, Department of Civil and Environmental Engineering, Arizona State University, Tempe, AZ

Ryu, H., Alum, A., Mena, K. D. and Abbaszadegan, M. (2007) 'Assessment of the risk of infection by Cryptosporidium and Giardia in non-potable reclaimed water', Water Science and Technology, vol 55, nos 1-2, pp283-90

Saint Lawrence Vision (2000) 'Consumption of drinking water', http://slv2000.qc.ca/ bibliotheque/centre_docum/bilan_sante/eau_potable/micro_organis_a.htm

Salgot, M., Huertas, E., Weber, S., Dott, W. and Hollender, J. (2006) 'Wastewater reuse and risk: Definition of key objectives', Desalination, no 187, pp29-40

Schönning, C., Westrell, T., Stenström, T.-A., Arnbjerg-Nielsen, K., Hasling, A. B., Hoibye, L. and Carlsen, A. (2007) 'Microbial risk assessment of local handling and use of human faeces', Journal of Water and Health, vol 5, no 1, pp117-28 
Shuval, H., Lampert, Y. and Fattal, B. (1997) 'Development of a risk assessment approach for evaluating wastewater reuse standards for agriculture', Water Science and Technology, vol 35, nos 11-12, pp15-20

Slifko, T. R., Smith, H. V. and Rose, J. B. (2000) 'Emerging parasite zoonoses associated with water and food', International Journal for Parasitology, vol 30, pp1379-93

Srikanth, R. and Naik, D. (2004) 'Prevalence of giardiasis due to wastewater reuse for agriculture in the suburbs of Asmara City, Eritrea', International Journal of Environmental Health Research, vol 14, no 1, pp43-52

Takumi, K., Teunis, P., Fonville, M., Vallee, I., Boireau, P., Nöckler, K. and van der Giessen, J. (2009) 'Transmission risk of human trichinellosis', Veterinary Parasitology, vol 159, nos 3-4, pp324-7

Teunis, P., Chappell, C. and Okhuysen, P. (2002a) 'Cryptosporidium dose response studies: Variation between isolates', Risk Analysis, vol 22, no 1, pp175-83

Teunis, P., Chappell, C. and Okhuysen, P. (2002b) 'Cryptosporidium dose response studies: Variation between hosts', Risk Analysis, vol 22, no 3, pp475-85

Teunis, P. F. M., Medema, G. J., Kruidenier, L. and Havelaar, A. H. (1997) 'Assessment of the risk of infection by Cryptosporidium or Giardia in drinking water from a surface water source', Water Research, vol 31, no 6, pp1333-46

Teunis, P. F. M., Moe, C. L., Liu, P., Miller, S., Lindesmith, L., Baric, R. S., LePendu, J. and Calderon, R. L. (2008a) 'Norwalk virus: How infectious is it?', Journal of Medical Virology, vol 80, no 8, pp1468-76

Teunis, P., Ogden, I. and Strachan, N. (2008b) 'Hierarchical dose response of E. coli O157: $\mathrm{H} 7$ from human outbreaks incorporating heterogeneity in exposure', Epidemiology and Infection, vol 36, no 6, pp761-70

Teunis, P., Takumi, K. and Shinagawa, K. (2004) 'Dose response for infection by Escherichia coli O157:H7 from outbreak data', Risk Analysis, vol 24, no 2, pp 401-7

Teunis, P., van den Brandhof, W., Nauta, M., Wagenaar, J., van den Kerkhof, H. and van Pelt, W. (2005) 'A reconsideration of the Campylobacter dose-response relation', Epidemiology and Infection, vol 133, no 4, pp583-92

USEPA (1993) 40 Code of Federal Regulations, Part 503, Fed. Regist. 58(32), 92489415

USEPA (1997) Exposure Factors Handbook, Vol II Food Ingestion Factors, National Centre for Environmental Assessment, Washington, DC

USEPA (2002) Child-Specific Factors Handbook, EPA/600/P-00/002B, National Centre for Environmental Assessment, Washington, DC

Wendel, A. M., Johnson, D. H., Sharapov, U., Grant, J., Archer, J. R., Monson, C., Koschmann, T. and Davis, J. P. (2009) 'Multistate outbreak of Escherichia coli O157: $\mathrm{H} 7$ infection associated with consumption of packaged spinach, August-September 2006: The Wisconsin investigation', Clinical Infection Diseases, vol 48, pp1079-86

Westrell, T., Schönning, C., Stenström, T.-A. and Ashbolt, N. J. (2004) 'QMRA (Quantitative Microbial Risk Assessment) and HACCP (Hazard Analysis and Critical Control Points) for management of pathogens in wastewater and sewage sludge treatment and reuse', Water Science and Technology, vol 50, no 2, pp23-30

WHO (2006) Guidelines for the Safe Use of Wastewater, Excreta and Greywater, World Health Organization, Geneva 
Yang, S., Benson, S. K., Du, C. and Healey, M. C. (2000) 'Infection of immunosuppressed C57BL/6N adult mice with a single oocyst of Cryptosporidium parvum', Journal of Parasitology, vol 86, no 4, pp884-7

Zmirou-Navier, D., Gofti-Laroche, L. and Hartemann, P. (2006) 'Waterborne microbial risk assessment: A population-based dose-response function for Giardia spp', BMC Public Health, vol 6, p122, www.biomedcentral.com/1471-2458/6/122 